\title{
El Frente de Estudiantes Sindicalistas. Una manifestación de la oposición falangista al régimen de Franco
}

Francisco Blanco MORal

Como situación previa a este comentario se hace preciso hacer referencia a dos realidades: la Falange, que durante el Régimen del general Franco pareció suministar la idología del Estado, y la aparición de movimientos contestatarios al sistema -al que nunca llegaron a inquietar en demasia - surgidos sobre todo desde finales de los cincuenta y agazapados en el mundo obrero y estudiantil. El frente de Estudiantes Sindicalistas (FES) participa de ambas realidades. Su carácter grupuscular, muy en consonancia con otras desidencias de aquel entonces, no empaña en nada el interés por el estudio de una opción original del falangismo no franquista.

Junto a la conducta de falangistización del Estado durante la guerra civil y en años posteriores es posible seguir un contrapunto de disidencia por parte de minoritarios sectores de falangistas que entendieron que el proyecto esbozado durante la República por los líderes históricos de Falange Española no se estaba cumpliendo.

A lo largo de la historia del movimiento falangista se pueden observar diferencias notables entre quienes se ampararon bajo dicha denominación. Así por ejemplo, en temas relacionados con la Iglesia católica, el mundo del trabajo o la universidad se produjeron posturas encontradas. Algo similar ocurriria con la aceptación del régimen, del Jefe del Estado 
o de las previsiones sucesorias ${ }^{1}$. Ante tamaña disparidad de criterios ¿no sería más correcto hablar de Falanges o de una Falange poliédrica en vez de hablar de Falange o de la Falange?

\section{MANIFESTACIONES DE LA OPOSICIÓN FALANGISTA AL REGIMEN}

La disidencia de falangistas hunde sus raices en el año 36 . Las dudas de José Antonio sobre participar en conjuras como mera fuerza auxiliar de choque se vieron desbordadas al comienzo del conflicto por el unánime apoyo de la Falange al bando nacional. En abril de 1937, a raíz del Decreto de Unificación y la negativa de Manuel Hedilla a aceptarlo, en cuanto a su forma, finalizó con las condenas de éste y otros falangistas.

Comenzaron a surgir grupos de descontentos como la Falange autética, las conjuras de algunos falangistas (Ruiz Arenado, González de Canales o Perales Herrero) o la Falange autónoma. Alguna mayor relevancia parecieron tener la Junta Política clandestina o las manifestaciones de inconformismo del coronel Yagüe, sin olvidar las ORNS (Ofensivas de Recobro Nacionalsindicalista) de Eduardo Ezquer ${ }^{2}$. Fundamentalmente manifestaban un estado de opinión, una exteriorización tímida de deseos. Actitudes de rebeldia que en aquel tiempo entrañaban enorme riesgo mezcladas con conspiraciones un tanto truculentas. El nombramiento de José Luis Arrese como Secretario General de la FET en 1941 inició una etapa de reconducción de la variedad falangista hacia la uniformidad, basada en doblegarse ante el catolicismo clerical que se iba imponiendo en el Estado.

En los años 50, en el Frente de Juventudes, dominado por el pensamiento falangista, era donde mayor grado de contestación se daba a

' El particular republicanismo de la Falange se vio matizado entre la mayoría de los falangistas por el asentimiento a cualquier medida proveniente del Jefe Nacional del Movimiento. No ocurrió asi en el caso del FES, pero falangistas históricos conocedores de la repulsa monárquica de su ideario ya en los años cuarenta especulaban con una posible vuelta a la monarquía. Ver JATO, D., "El futuro de la monarquía", en El Alcázar, 10-IV-73.

${ }^{2}$ La trayectoria de disidencia falangistas puede seguirse a través de los textos siguientes: MıA, E., Falange Española 1937-82. Los años oscuros, $1 .^{2}$ ed., Barcelona, ed. Alternativa. Noviembre 1986. PAYNE, S., Falange, Historia del fascismo español. Paris, Ruedo Ibérico, 1965. Romero Cuesta, A., Objetivo: Matar a Franco. Madrid, Ed. 99, 1976. Onrubia, J., Historia de la oposición falangista al régimen de Franco en sus documentos (I). Madrid, Ed. del autor, 1989. ElLwood, S., Prietas las Filas, Barcelona, Grijalbo, 1984. 
la política institucional. Desde aquella organización y en busca de la pureza falangista se articularon núcleos que realizaron algún tipo de propaganda con el nombre de JANS (Juntas de Acción Nacional Sindicalista) a principios de los 50 y con el nombre de JONS (Juntas de Ofensiva Nacional Sindicalista) en el final de la década. Actitudes testimoniales como aquella centuria de militantes juveniles que dio media vuelta al pasar el Jefe del Estado en El Escorial (1955) o la de aFranco eres un traidor!n del militante juvenil Alonso Urdiales (1960) convenientemente depurado tras el incidente.

Insatisfacción se respiraba en el núcleo santanderino Haz lbérico y lo mismo ocurría en el grupo que, con estructura celular, se formó en las dependencias del Movimiento en la calle Cinco Rosas en el distrito madrileño de Carabanchel y que acabaria siendo engullido por el PCE. Así pues junto a la Falange, fiel servidora del Estado, habia pequeños grupos de descontentos que seguian luchando por la "revolución pendiente", pero siempre con un pie dentro del partido único. Disidencias espontáneas, sentimentales, irreflexivas y desde luego, contradictorias.

Aquel malestar era conocido en El Pardo. El 14 de febrero de 1956 José Luis Arrese había sido llamado por Franco y relata que «El Caudillo (estaba) incómodo con una Falange que se le iba de las manos" ${ }^{3}$. El intento "constitucional» emprendido por el ministro falangista se vio abocado al fracaso por las prediones de otros sectores como el Ejército o la Iglesia. La pérdida de influencia de los falangistas hacía que estos pensaran en la necesidad de falangistizar el Estado. En 1959 en el Hogar "Medina" de la Sección Femenina se fundó el círculo doctrinal "José Antonio".

La actitud contradictoria de estar en contra del Régimen, pero mantenerse dentro de él se intentó superar con la creación del Frente de Estudiantes Sindicalistas ya que estos ni se vinculan a organizaciones del Movimiento ni pretendian falangistizar el régimen.

\section{LA ORGANIZACIÓN}

El conglomerado conocido como FES abarcaba cuatro organizaciones diferentes aun cuando se impusieran siempre esas siglas que llega16.

${ }^{3}$ Arrese Magra, J. L. de, Una Etapa constituyente, Barcelona, Ed. Planeta, 1982, p. 
ron a ser confundidas con una "Falange Española Sindicalista". Al amparo de la etiqueta FES se hicieron claras manifestaciones de tipo político que nada tenían que ver con el cometido estrictamente estudiantil. El grado de militancia de los afiliados y la edad de los mismos eran los condicionantes para situarse en una $u$ otra estructura. Un "Código del militante" establecia cuáles eran las obligaciones a que se comprometía el integrande del grupo falangista, informado de un sentido altamente jerarquizado y asumiendo características propias de la vida de milicia.

Hacia el año 63 surgen los protonúcleos de este conglomerado con el nombre de "Juventudes Falangistas" que se convertíría con el tiempo en una élite de dura militancia y que haría las veces de un "Comité central" desde donde se controlaba a las demás organizaciones. Supervisando todo aquello aparece siempre la figura de Sigfredo Hillers de Luque ${ }^{4}$.

El «Frente de Estudiantes Sindicalistas". En sentido estricto, era el brazo operativo de la organización. La participación en la algarada estudiantil o las acciones políticas eran su principal cometido. La sección universitaria era la más numerosa, aunque desde finales de los años sesenta se creó una sección nutriente entre los estudiantes de enseñanzas media, el FES de Bachiller, que con López Créstar y José M. ${ }^{a}$ Aznar como responsables procuraban la falangistización de jóvenes estudiantes en los moldes marcados por la organización.

La "Asociación Juvenil Octubre", remedo en miniatura del Frente de Juventudes, se fundó el 12 de octubre de 1971 y se insertaba en el marco del asociacionismo juvenil de la época. Aceptaba los cauces legales para el desarrollo de sus actividades dejando para el FES aquellas actuaciones no sujetas a ley. El sucedáneo de asociación política que aquello representaba fue puesto de manifiesto a raíz de su fundación por publicaciones como Ya, Voz de Asturias o Tele Exprés.

4 Sigfredo Hillers de Luque fue cofundador del FES - junto a Ceferino L. Maestu Barrios- en el año 1963. Provenía del Frente de Juventudes. Ideólogo de la primera organización falangista al margen del Movimiento, despertaba admiraciones entre sus seguidores y animadversiones de sus contrincantes políticos. De talante autoritario y extremadamente intransigente pasó a sufrir el descrédito por parte de muchos falangistas que habian visto en él al verdadero intérprete de la Falange. Su fuerte critica contra el franquismo en los años 60 se tornó al final del período en establecer puentes de unión con sectores azulados del Régimen y, aun no olvidando la crítica, procuraba suavizar los juicios contra los falangistas franquistas. Recientemente ha estado en el candelero informativo por problemas en torno a cuestiones de uso de material didáctico y sobre todo por su interpretación de la actitud del rey D. Juan Carlos ante el golpe de estado del 23-F. 
El "Círculo Ruiz de Alda" era la plataforma legal para los militantes más veteranos aunque su estatuto fundacional hablara de una asociación de jóvenes. Se constituyó al amparo de la Ley de Asociaciones de 1964 y su objetivo formal era una mezcla de fines políticos y de una pretendida extensión cultural en torno a lo que significaba la doctrina de la Falange. Sus actividades se redujeron a periódicas charlas, apoyo en actividades del FES y, en el ultimísimo tramo del franquismo, a la confección de un boletín informativo.

Aparte de los dos centenares de panfletos distintos que el FES edita desde 1963 a 1977 las publicaciones períodicas del FES las constituyeron los periódicos Resurgir, Misión y los boletines de la Asociación Juvenil Octubre y del Circulo Ruiz de Alda. Anteriormente habia visto la luz la revista Sindicalismo, de la que se publicaron cinco números. Su contenido era obrerista y su promotor Ceferino Maestú. Fue prohibida en época de Fraga como Ministro de información. Las publicaciones del FES estaban fuertemente teñidas de ideología y resultaba curioso que a partir de los intentos de unidad falangista del 1973 dejara de aparece la revista Misión. Su hueco lo iban a llenar los boletines de los órganos legales, tanto de la AJO como y sobre todo, el del Círculo Ruiz de Alda. Podria decirse que las publicaciones Resurgir y Misión se dedicaron a hostigar el revisionismo derechista de la Falange, fundamentalmente al Movimiento Nacional, mientras que los boletines citados acometían contra la revisión izquierdista que representaron los hedillistas.

\section{FORMARÉ JUNTO A MIS COMPAÑEROS}

En la época en que aparece el FES existian otros grupos falangistas. Podrían distinguirse entre ellos los que orgánicamente estaban integrados en el Movimiento como Sección Femenina o la Guardia de Franco y aquellos otros que con estatus legal, aun no estando orgánicamente vinculados al Partido únido mantenían contactos y cierta dependencia legal, asi ocurría con los Círculos José Antonio y con la Agrupación de Antiguos Miembros del Frente de Juventudes. Ambas organizaciones recogían sobre todo a falangistas que veían con nostalgia el cambio que se estaba produciendo dentro del Régimen.

Para el FES la unión de todos los falangistas fue desde el principio un objetivo prioritario, posiblemente sólo superado por distinguir claramente la diferencia entre Movimiento y Falange. Desde 1965 se habian mantenido contactos con la AAMMFJJ, la idea del FES pasaba por la 
formación de una Federación de Grupos Falangistas. No se llegó a ningún acuerdo concreto favorecedor de la unidad. Reuniones esporádicas con los Círculos José Antonio desde el 65 fraguaron en 1969. El 29 de noviembre de aquel año se anunciaban los intentos de formar la asociación FE de las JONS. En 1970 se crearon unas Juntas Promotoras de FE de las JONS. Se procedía a la crítica contra quienes habían entendido el ser falangista, primero, como un oficio y, más tarde, como una vergüenza inconfesable. La mayor realización de aquella intentona de unidad fue la $1 .^{\text {a }}$ Concentración falangista celebrada en Alicante en 1970, reprimida por la policía y la guardia civil y en donde resultaron detenidos militantes de los Círculos y del FES ${ }^{5}$. Presenció el año siguiente el final del proyecto unitario. Una nueva concentración, esta vez en el Valle de los Caídos, se vio desasistida por parte de los Círculos, quienes en una maniobra de confusión convocaron en día distinto. 150.000 pesetas pagadas por la Secretaría General del Movimiento, según el Frente de Estudiantes Sindicalistas, habian propiciado la ruptura. Resultaba difícil que personas afines a las parcelas del Movimiento pudieran plantarle cara de forma continuada. Para los jóvenes falangistas, los Círculos pasaban a ser "vehículos de la corrupción".

Un hecho de gran importancia será la publicación en 1973 del libro Falange hoy ${ }^{6}$, en donde falangistas de distintas tendencias exponian sus puntos de vista al cuestionario enviado por los periodistas Veyrat y $\mathrm{Na}$ vas-Migueloa. A pesar de tanta controversia se había abierto una vía de diálogo entre las distintas corrientes a partir de la publicación del libro. El envejecimiento del Jefe del Estado, los poderes de otras familias del régimen, los interrogantes sobre la salida a la muerte del Generalísimo auspiciaban estos intentos que a la larga se revelarían inútiles. El 9 de abril del 73 en el Colegio Mayor "José Miguel Guitarte" -dirigido en aquella época por un miembro del FES - se organizaba una charla coloquio con la participación del Sigfredo Hillers, Manuel Cantarero y Raimundo Fernández Cuesta. Repetían sus viejas posiciones, aunque el hecho de hacer un acto conjunto posturas hasta entonces irreconciliables, daba lugar a la esperanza.

Manuel Cantarero del Castillo (futuro integrante del grupo Popular) presentaba una curiosa revisión del falangismo. El Presidente de la Agrupación de Antiguos Miembros del Frente de Juventudes pretendía reconciliar el pensamiento falangista con el socialismo democrático. Para el

5 OnRuBia, J., obra citada, pág. 20.

6 Veyrat, M. y Navas-Migueloa, J., Falange hoy. Madrid, Gregorio del Toro, 1973. 
FES tal proyecto era absolutamente inválido y fue calificado de "socialismo rosa". Llegarían a acusar a Cantarero de un doble juego consistente en su posición vergonzante hacia la Falange de una parte y por otra, su colaboración en la revista Haz desde donde propugnaba la resurrección del SEU. A la publicación del texto Falange y Socialismo?. Hillers preparó toda la artillería a su alcance para neutralizar el intento de Cantarero que pasaría de ser considerado un revisionista con algunos valores positivos a la visión de hereje-oportunista.

Con el pretexto de presentación del libro Falange hoy a los falangista en el Club "Don Hilarión", José Gárate Murillo, considerado hombre de confianza de José Antonio Girón, propuso a Hillers establecer reuniones entre los distintos grupos. Prosiguieron los contactos y se llegó incluso a conseguir la vieja aspiración del FES, formar una Federación de Grupos Falangistas. Era la época del asociacionismo de Arias y la Federación se aprestaba a formar una asociación con el nombre de Frente Español, cuyas iniciales coincidian con las de la Falange Española, titulación que "al ser patrimonio de todos los españoles" no se otorgaba a ningún intento asociativo.

La Federación llegó a su fin en julio del 75. La figura del general Franco y todo to que ella representaba era un obstáculo insalvable. La devoción de los falangistas históricos hacia el Caudillo no era asumida en absoluto por los jóvenes, y lo que resultaba más grave, remover aquello, que no era sino analizar la historia, destapaba la caja de los truenos. Según algunos de los presentes planeó por allí el fantasma de Salamanca, abril de 1937 y pudo terminar la reunión "como el rosario de la aurora" ${ }^{8}$. Un intento a la desesperada conocido como el "Pacto de Matute» logró José Gárate. El grupo falangista que consiguiera el nombre: de Falange Española convocaria un congreso con todos los demás.

La concesión del histórico nombre a la facción que acaudillaba Fernández Cuesta reavivó los intentos de unidad. Se preparó para ello un acto al que acudia el Frente de Estudiantes Sindicalistas en el Palacio de Congresos y Exposiciones de Madrid el 29 de octubre de 1976. Aquel espejismo de hermandad falangista finalizaba en bofetadas a poco del comienzo de la intervención de Hillers de Luque ${ }^{9}$.

\footnotetext{
7 Cantarero del Castillo, M., Falange y Socialismo. Barcelona, Dopesa, 1976.

8 Ya, 03-VII-75.

$9 A B C, 30-\mathrm{X}-76$ y El Pais, 30-X-76.
} 


\section{EL HEDILLISMO}

Aunque la disidencia falangista ha contado con el adjetivo de "hedillista", nunca el FES utilizó de tal calificativo. Muy al final del régimen surgirian grupos hedillistas que desplegaron amplias campañas de propaganda y mantuvieron relaciones hostiles con el FES.

La figura del que fuera II Jefe Nacional de FE de las JONS presentaba para el FES sentimientos encontrados. La dimensión personal de Manuel Hedilla, su fidelidad a José Antonio, su talante organizador de la Falange en los primeros meses del Alzamiento y el sufrimiento al que se vio sometido tras la Unificación eran dignos de la más profunda admiración; sin embargo, su postura política presentaba claroscuros que dificultaban la adhesión del FES ${ }^{10}$.

Si la figura de Hedilla tuvo para el Frente cierta admiración, no hubo ningún tipo de concesión hacia los denominados «hedillistas" que aparecieron en el tardofranquismo y asumieron una estrategia de propaganda con golpes de efectos. Los miembros de este movimiento "hedillistas", que acabarán como FE de las JONS auténtica, eran producto de las escisiones del FES de los años 67 y 72, miembros de FINAL reconvertidos y afiliados al Movimiento que veian su barco hundirse. La opinión pública durante la transición identificaba la rebeldía falangista con el «hedillismo».

Fueron múltiples los enfrentamientos entre el FES y los hedillistas; éstos acusaban al FES de progresiva derechización y de darle una importancia desmesurada al catolicismo como filosofía y praxis. El FES reproducia ataques en sus publicaciones contra estos falangistas "histéricos" contraposición de los falangistas «históricos". Les juzgaba como una versión izquierdista de la Falange al igual que la Falange del Movimiento había supuesto la versión derechista de la misma y les consideraba «fieles discípulos de los mercaderes del Movimiento Nacional».

El enfrentamiento entre el FES y los hedillistas alcanzó su máxima virulencia en abril del 77 a la salida de la presentación del libro Oferta electoral en el Hotel Eurobuilding. Allí Sigfredo Hillers, líder del FES, ya

${ }^{10}$ En conversaciones mantenidas con miembros del FES en 1968, Manuel Hedilla manifestaba su deseo de no entrar en agrupación alguna que portara los nombres de "Falange" o de "revolucionario". Discrepancias mantenidas con el FES por aquel entonces llevaron a una posterior falta de comunicación entre el grupo falangista y el II Jefe Nacional de FE de las JONS. 
convertido en Falange Española Independiente, fue agredido por miembros de la Falange auténtica. La tenencia en el altercado de guanteletes de hierro, porras y navajas, así como la información dada por Cambio $16{ }^{11}$ con el nombre de algún agresor, iban a ser, según Hillers, argumentos utilizados para pedir al Tribunal Supremo la ilegalización de este grupo.

No había pues lugares comunes para la unidad de la Falange. La Santa Hermandad de la Falange no dejaba de ser un latiguillo retórico en donde se imponían luchas cainitas.

\section{RELACIONES CON LA EXTREMA DERECHA}

Aun cuando la mayoría de analistas han encasillado al FES en el compartimento de "extrema derecha", un estudio detallado de sus posiciones los sitúa bastante alejados de esa "derecha nacional». Las relaciones mantenidas con Defensa Universitaria o con el AUN en la universidad fueron siempre tirantes y el FES se esforzaba por deslindar su ideología y sus métodos de acción de los grupos citados por lo que resultaron frecuentes los enfrentamientos verbales y en ocasiones también los físicos. En opinión de la opción de derecha nacional más conocida, Fuerza Nueva, el FES servía al juego de los comunistas. Este situarles de "tontos últiles" no era admitido por el FES para quienes quedaba claro que era Fuerza Nueva quien daba cancha a la izquierda defendiendo las injusticias que habia generado el Estado del 18 de Julio.

Mayor repulsa merecian para los falangistas el grupo de los "Guerrilleros de Cristo Rey" sobre todo por los métodos violentos utilizados y por usar simbología falangista. Por la utilización de aquellas vestiduras, indignas para quienes las llevaban en opinión del FES, fueron criticadas las concentraciones de la Plaza de Oriente de 1971 donde voivia a repetirse, una vez más, el «acompañamiento coreográfico de nuestras camisas azules".

\section{LA DEFINICIÓN DOCTRINAL}

Dos contantes resumen la ideología del grupo: su falangismo joseantoniano y su catolicismo. Se repetía casi literalmente el pensamiento de

${ }^{11}$ Cambio 16, 17-IV-77. 
Primo de Rivera, el hombre era considerado "portador de valores eternos". La Patria era "unidad de destino en lo universal» y el Estado ejecutor de los destinos de la Patria. Inmersos en la cosmovisión de José Antonio veían la política como algo completo, total. Se preparaban a la formación de una milicia que asumiera voluntariamente valores religiosos. Esa vía más ética que otra cosa, diferenciaba claramente las formas de actuación de los contenidos coyunturales, para lo primero estaba el modo de ser falangista, para lo segundo se diseñaba, allí y entonces, lo que se habia dado en llamar el nacionalsindicalismo con posibilidades de recambio cuando su utilidad instrumental pudiera quedar obsoleta. Como sintesis de la forma de actuación del falangista del FES se iniciaron desde los primeros tiempos de la organización la redacción de normas básicas mediante pequeñas frases o consignas. Una especie de breviario al que se le dio forma de libro con el título de Ética y estilo falangista ${ }^{12}$. En esa interesante obra cuya similitud con Camino es evidente, se exigía por ser el mayor seguro para la continuación de las propuestas políticas de José Antonio, la fidelidad en la conducta y un compromiso total con la Falange. El categórico rechazo a que la Falange fuera una especie de "mafia" para ayuda y colocación de sus miembros contrastaba con las bicocas de uso corriente que ser de la FET había porporcionado; la caridad con los enemigos políticos tampoco había sido moneda de cambio en el falangismo, y sin embargo desde el libro se exigían tales cualidades para poder llegar a ser y a ejercer de falangista.

La postura diseñada por la Falange hacia la Iglesia habia sido de sumisión en el terreno ideológico-moral y de separación de funciones en el plano político. Durante la guerra civil y los primeros tiempos de la conflagración mundial se asistió a una lucha entre los sectores más totalitarios del Partido y la Iglesia católica, que terminó con el sometimiento de la Falange a las imposiciones eclesiales ${ }^{13}$. Desde su fundación las organizaciones más falangistas del régimen contaron con el influjo de la

${ }^{12}$ El Etica y estilo falangista libro que consta de 407 puntos o consignas sobre el comportamiento para «llegar a ser y ejercer de falangista» llegó a ser el libro de cabecera de los militantes del FES. Publicado con aportaciones personales de los miembros del grupo y de algún otro falangista, consta de tres partes: La primera donde falangistas de distintos lugares y tendencias juzgan la obra; la segunda, en donde se relata la génesis del texto $y$, la tercera, que es propiamente la obra, es decir, la relación de las consignas reseñadas.

13 Sobre las tensiones existentes entre la Iglesia y la falange resultan significativas las obras siguientes: Hermet, G., Los católicos en la España franquista, 1. ${ }^{\text {a }}$ ed., Madrid, Siglo XXI, 1985. SuÁRez Fernandez, L., Francisco Franco y su tiempo, Madrid, Fundación Francisco Franco, 1984. TuSEll GoMez, J., Franco y los católicos. La política interior española entre 1945 y 1957. Madrid, Alianza Editorial. 
Iglesia católica en sus presupuestos ideológicos y con la participación de religiosos en sus quehaceres. En las formaciones juveniles y en los sindicatos existian asesores religiosos. La moral católica era asumida y estudiada en las parcelas más azules del régimen ${ }^{14}$.

Para el FES seguía siendo necesaria la separación entre la Iglesia y el Estado. la Iglesia no debía intervenir en política y el Estado no debía inmiscuirse en cuestiones internas de la propia Iglesia como ocurria con el histórico Derecho de Presentación al que se obcecaba en no abandonar.

En lo referido a la doctrina se acoplaba el FES a los cauces más integristas de la Iglesia católica mientras que en el aspecto relativo al poder social de la Iglesia apuntaba soluciones mucho más progresistas (crítica al clero encumbrado o al negocio-explotación que la Iglesia tenía montado en base a la enseñanza).

De entre las formaciones católicas con proyección en la política merece destacarse, por el papel que desde finales de los 50 representaron, al Opus Dei. La critica que el FES hizo a la Obra se basaba no en aspectos políticos (sustitución de falangistas por opusdeistas en tareas de responsabilidad) sino por entender, con evidente error de apreciación, que esa organización religiosa había fracasado porque el doble objetivo de santificar a sus miembros y santificar a la sociedad no se había logrado.

Entre los conceptos vertebradores de su discurso y por ser los más repetidos merecen resaltarse los siguientes: La Patria, que anclada en el concepto joseantoniano resultaba inexistente; el tema de participación política en donde la democracia orgánica, malentendida y falseada por el Régimen según el FES, seguia siendo la forma de integrarse en los resortes del Estado; el capitalismo, cuya destrucción era una tarea de indole moral; el patriotismo-nacionalismo, que conllevaba amplias dosis de antiamericanismo; el anticomunismo en donde el FES entendía que su posición era la de "competencia revolucionaria" huyendo de las actitudes defensivas o represivas de otros camisas azules; y la juventud a la que se otorgaba valor de categoria histórica y no de tránsito evolutivo, pero de la que el FES se vería mayoritariamente desasistido.

${ }^{14}$ Sobre religiosidad del Frente de Juventudes y de las OO.JJ. en SaEz Marin, J., EI Frente de Juventudes, Madrid, 1 , $^{\text {a }}$ ed., Siglo XXI, octubre de 1988, pp. 81, 128, 159, 172. ALCOCER, J. L., Radiografia de un fraude, Barcelona, Planeta, 1978, p. 196. 
La actitud crítica hacia el entorno, propia de un grupo que se definia como opositor, llevaba al FES a un maximalismo crítico en donde el paro, la emigración, la conciencia adormecida de la juventud, la explotación capitalista, la pequeñez de España en el concierto internacional o el dominio económico y militar de potencias extranjeras eran sistemáticamente denunciados.

\section{LOS FRENTES DE LUCHA}

Los sectores donde más se podía significar un grupo político eran el obrero y el estudiantil y por supuesto que una opción que se preciaba de innovadora tenía que dirigir sus invectivas contras el inmovilismo institucional, centrado muy particularmente en el Partido Único al que interpretaban como falsificador de la Falange.

\section{El Movimiento obrero}

La critica que se realizaba al sistema capitalista podría haber sido asumida por cualquier integrante de la oposición de izquierda. No existía el mínimo alborozo por las realizaciones de Régimen por parte de esta Falange que intentaba conseguir prestigio entre las filas de los trabajadores. De claro contenido falangista aun cuando faltara la parafernalia al uso era la revista Sindicalismo publicada en 1964, con tan solo cinco número publicados. Ceferino Maestú era el ideólogo de la publicación y no cabe duda que alli se expresaba el sentimiento sindical de grupo falangista ${ }^{15}$.

De tono parecido eran las cartas que firmadas por Hillers, Carmena e Izquierdo y dirigidas a mandos de la Organización Juvenil atacaban a los ministros de Trabajo y Comercio y exigian la imperiosa necesidad de que existieran sindicatos falangistas.

Fue también en el año 64 cuando en dependencias del Movimiento, en el Centro Social Manuel Mateo, miembros del PCE que se guarnecian con el título socialdemócratas mantuvieron contactos, pronto rotos, con

${ }^{15}$ La postura sindical falangista de Ceferino Maestú puede seguirse en Es asi n. ${ }^{\circ}, 01$ 1-63. Revista Sindicalismo. La Reforma de la empresa (folleto a ciclostil en donde se reúnen los temas tratados en las charlas de La Ballena Alegre). 
falangistas disidentes como Maestú, Perales, Pérez Garijo o Socorro Delgado. Ceferino Maestú había acudido con las siglas UTS (Unión de Trabajadores Sindicalistas) a la creación de la comisión de los 16. El abandono temprano de este líder sindical de las posiciones falangistas hizo que el relevo lo tomara el histórico Narciso Perales que utiliza las siglas FNT (Frente Nacional de Trabajadores) en los intentos de lucha obrera.

La consideración de que la Organización Sindical era el arma de opresión del que servía la plutocracia les hacía descartar cualquier contacto con el sindicato vertical y pedir el boicot a las elecciones de 1966. La pretensión de FNT, rayana en la utopia, al igual que la de las formaciones más a la izquierda, se resumían en crear un sindicato único, libre, representativo y obligatorio y luchar por la desaparición del capitalismo.

Participaron estos falangistas en los conflictos de la Standard-Marconi utilizando un análisis y un lenguaje producto de la asimilación izquierdista. Asi por ejemplo no dudaban en utilizar frases como "Por qué hemos de ser los trabajadores los que suframos las consecuencias? ¿Que inviertan los millones de pesetas repartidos como botín del robo de nuestro sudor en solucionar la crisis". De igual manera hicieron una distinción básica entre trabajo, fuerza de trabajo y remuneración.

Con el nombre de Falange Nueva ${ }^{16}$ se lanzó propaganda contra Solís Ruiz "El Delegado Nacional de Sindicatos que no son sindicatos" a propósito de la fijación del salario mínimo. En abril del 67 FNT denunciaba "a todos los estudiantes" la miseria del convenio de la Banca y convocaba a una manifestación ante el cine Carlos III de Madrid en donde se habría de celebrar una Junta de accionistas. Ese año marca el final de los escarceos de esta Falange alternativa con organización propia en el mundo del trabajo. No faltarán críticas y esbozos de soluciones a partir de entonces, pero ya sin una organización específica.

En los sucesos de octubre de 1970 en Granada el FES organizó con ese nombre al no existir una plataforma de lucha especificamente obrera y llegó en su publicaciones a acusar tanto al gobierno como al PCE de reprimir la huelga general convocada para el 21 de octubre.

Experiencias desagradables en un sector donde el combate era muy duro, el escaso eco de la protesta falangista entre los trabajadores y la

${ }^{16}$ El nombre de Falange Nueva fue escasamente utilizado al resultar semejante al que por entonces portaban movimientos neofascistas en Europa y de los que se intentaba evitar cualquier aproximación. 
falta de definición clara en temas como el de la libertad sindical -producto del dogmatismo ídeológico que tenían- acabaron por conducir al fracaso este frente de lucha.

\section{El Movimiento estudiantil}

De mucha mayor importancia será la entrada en el mundo universitario ${ }^{17}$. El 1 de abril de 1964 hizo su aparición en público el FES mediante un manifesto dirigido "A todos los estudiantes". El Frente entendía ser el eslabón con el SEU de tiempos de la República no con la entidad de control que bajo el mismo nombre actuaba en la universidad. La lucha contra este SEU era compartida con otras formaciones universitarias de oposición.

Pensaban que el problema universitario tendría solución con las medidas que el FES propuso de forma reiterada a lo largo de su existencia y que se resumian en: Estatuto del estudiante; Sindicato único, libre, democrático y representativo; abolición de la cátedra vitalicia y acceso de los trabajadores a la Universidad. Para que este último punto se hiciera viable el Frente exigía del gobierno "medidas de excepción".

En un principio el papel del sindicato estudiantil se lo pensaba el FES para sí. En consecuencia no exigia la militancia falangista para la pertenencia al grupo, pero acontecimientos internos de la organización y los externos a ella, es decir, la radicalización política de las minorias actuales, acabarian por condenar al FES a ser un grupo estrictamente falangista.

Los problemas por los que atravesaba la Universidad en febrero del 65 se valoraron como de "violencia, arrestos y multas", pidiéndose la destitución del responsable de la brutal carga del 24 de febrero, la libertad de los detenidos, la condonación del multas, la reintegración de los profesores expedientados y la abolición del Estatuto Ordenador del 43.

En octubre del 65 una Central Valenciana de Estudiantes Sindicalistas hizo su aparición. Dado que sus puntos programáticos referidos a la

"Valoraciones acerca del significado político y universitario del FES pueden encontrarse en: SAÑA, H., "La Falange: intento de un diagnóstico" en indice de las letras $y$ de las artes, n. 269 y 270 de $15-\mathrm{V}-70$ y 01-VI-70. CORA, J. DE, Panfletos y prensa antifranquista clandestina, Madrid, Ediciones 99, 1977. ANUE, n.25 y Avanzada, febrero de 1975. 
Universidad eran idénticos a los del FES se produjo su integración. Algo similar ocurría con las Falanges Universitarias de Navarra que, integradas en el FES, hicieron suyo el deseo de separación de la Falange del Movimiento.

La época del sindicato Democrático contó también con la participación de los falangistas. Miembros del grupo fueron elegidos delegados en algunas facultades aún cuando la extensión a todo el estudiantado no llegó a producirse.

La acción de FES continúa con la denuncia del traslado del selectivo de la facultad de Filosofia a Aravaca, la reestructuración de la Escuela de Graduados Sociales a la convocatoria a la huelga en protesta por el juicio que contra representantes del Congreso de Distrito de Barcelona se iban a celebrar.

Dos importantes documentos ven la luz de 1967: La «Proclama a la Universidad Españolas en donde se denunciaba el estado de la universidad como reflejo de la situación social de España y el "Manifiesto a las Juventudes de España" que, con un título de claros recuerdos jonsistas, insistia en la necesidad cristiana del compromiso político ante la realidad nacional.

El año 68 se producía el cierre de la Universidad madrileña con la consiguiente denuncia de los grupos políticos entre ellos del FES, al igual que ocurría con la creación de la policia universitaria. Por esta época comenzaban los inicios de la Reforma educativa del tecnócrata Villar. La critica que realizaba el FES ponia en el bando opositor tendencias que no eran homogéneas. El paso del tiempo ha valorado positivamente la emprendida en el 70 en donde se adecuaba en parte el sistema de enseñanza a la realidad socieconómica que en España se daba, pero el dogmatismo de las formaciones políticas no podía aceptar aquello porque pensaban que el capitalismo podía ser vencido. Los universitarios falangistas elaboraron, con sus planteamientos de siempre, un «Proyecto de reforma universitaria".

A la propuesta del Subsecretario de Educación, Díaz Hotleichner sobre aportación de sugerencias para el Libro Blanco de la Reforma educativa, el FES envió su vieja idea de acceso de los trabajadores a la universidad sin la necesidad de tener que cursar el Bachilleraro y la propuesta de un Estatuto del estudiante.

Desde 1970 el discurrir del FES se centra más en los temas políticos $y$ en el mundo de la Falange. No es que se olvide el tema estudiantil pero el asunto politico interesa más que nunca. Como producciones más 
destacadas estuvieron la confección de un estudio, ampliamente difundido, sobre los problemas de la sanidad en España y la respuesta FES ante los rumores de refundación del SEU.

El sistema de participación estudiantil de 1974 tampoco convencia y se le acusaba de dirigista, pero eso era ya lo de menos. Se atisbaba el final del régimen y el FES tenía que dar una opción clara en la etapa que se avecinaba. Por "genio y figura" el año 75 vio panfletos de FES sobre acción política y sindical en la universidad y la crítica a los "actos de gamberrismo" que se producian en algunas facultades madrileñas.

La muerte del general Franco, hecha coincidir con la del fundador de la Falange, cogió al FES en sus habituales cometidos de rememoración que llenaban una especie de calendario litúrgico y que abarcaban el 29 de octubre, 20 de noviembre y el 9 de febrero.

\section{El inmovilismo institucional}

Desde los primeros tiempos estuvo el Movimiento Nacional en el punto de mira del FES que acuñó como slogan favorito el «Falange sí, Movimiento no". Se entendía que el Movimiento era la falsificación de la Falange y la respuesta consistió en el "zancadilleo», teniendo muy en cuenta las posibilidades de acción de esta minoría minoritaria.

Los actos rituales conmemorativos de la fundación de la Falange o de la muerte de José Antonio contaron con el boicot, mediante la asistencia provocadora de incidentes, o bien realizando actos paralelos "al margen del aparato oficial». La salida de la corona de laurel que todos los 19 de noviembre y con destino al Valle de los Caídos se hacia desde la Cuesta de Santo Domingo contaba con la asistencia del FES. Los incidentes producidos hicieron que las autoridades trasladaron el acto a las afueras de la capital. Alli acudian también los militantes del FES, quien con su actitud y el reparto de propaganda antirrégimen provocaban el enfrentamiento con francofalangistas o la intervención de la policia.

El funeral por José Antonio en la iglesia de San José los 20 de noviembre o el Matías Montero en Corazón de María iban seguidos de incidentes en las calles madrileñas con la consecuente actuación policial. Aquel tipo de actuaciones con las consiguientes detenciones esporádicas y el apaleamiento de rigor daba sentido al activismo del FES que veía dirigirse contra ellos la represión del Estado. Se sentian una «Falange 
perseguida" y presentaban aquello como la respuesta que el Régimen daba al desenmascaramiento que ellos estaban propiciando.

Cuando se sometió a referéndum la Ley Orgánica del Estado, en donde el FES solicitaba el voto negativo, se distribuyó un escrito titulado "Carta de un falangista al Jefe del Estado" en donde Hillers, sin que su nombre apareciese, criticaba la decisión tomada por el general, calificando de "burla" al referéndum. Varios falangistas, entre ellos el propio Hillers fueron detenidos. Los falangistas del Movimiento hacian una fuerte campaña a favor del sí y, como afirmaba Hillers al final de su carta en donde justificaba el anonimato: "tampoco faltarán jerarquías del Movimiento dispuestas a denunciarnos".

Cuando en ese mismo año de 1966 la jefatura del Movimiento de Madrid organizó una campaña de "recuperación de la calle» con mítines en cines madrileños, el FES acudia a los mismos con intenciones boicoteadoras enfrentándose a los oradores y a la policia.

De mayor resonancia y a juicio del FES por ello provocado, fue la suspensión del acto del Teatro de la Comedia, conmemorativo de la fundación de la Falange. Gritos e insultos contra el ministro Secretario, reparto de propaganda y choques físicos entre falangistas de distintas tendencias propiciaron el traslado del escenario al Consejo Nacional del Movimiento.

Los intentos organizados desde la Delegación Nacional de la Juventud de montar albergues y campamentos tendentes a la formación de una especie de frente anticomunista universitario, contaron también con la actitud contraria del FES que denunciaban el carácter reaccionario que ello representaba.

Sin embargo una aparente contradicción entre la dialéctica histórica FES-Movimiento comenzaba a partir de 1972. Tres hechos daban lugar a ello: La asesoría de José Cabanas, dirigente del FES, en la Delegación Nacional de la Juventud, la concesión de la Dirección del Colegio Mayor "José Miguel Guitarte" a otro dirigente del FES, Antonio Hermoso, y la participación en uno de los múltiples miniatentados que contra la película "La Prima Angélica" de Carlos Saura se realizaron en Madrid. Los dos primeros hechos aparecian como gratuitas concesiones amparadas por el Vicesecretario General Valdés Larrañaga que parecía intentar la aproximación al grupo falangista; el esperpéntico ataque contra la película citada -motivo de enfrentamiento en el interior de la organización- se rumoreaba que contaba con el visto bueno de Presidente de las Cortes, Rodríguez de Valcárcel. 
Aprovechando los intentos aperturistas de la Delegación Nacional de la Juventud, que se disponía a hacer electiva la presidencia de la Asamblea Nacional de Jóvenes en 1974, Jesús Ferrer, Presidente de la AJO, consiguió ser elegido democráticamente Presidente de aquel organismo. A un mes de aquel triunfo comenzaron los problemas. Desde la Delegación de la Juventud se le indicó a Ferrer que debía participar en un "Homenaje de la juventud española al General Franco", previsto para el 8 de diciembre de 1974, Jesús Ferrer dilató su decisión amparándose en que fuera el Pleno de la Asamblea Nacional de Jóvenes quien decidiera. Comprendiendo la actitud de rechazo, la Delegación de la Juventud convocó a la Comisión Permanente y destituyó a Ferrer por «incumplimiento notorio de sus funciones". La destitución a la que el FES dio el calificativo de "purga" servía ahora para criticar acremente los estatutos de la Asamblea Nacional, dado que su dependencia de la Delegación Nacional de la Juventud hacía imposible la autonomía del asociacionismo juvenil.

La figura del Jefe Nacional del Movimiento se contemplaba lejos de la loa a la infalibilidad que le suponian sus allegados y también distante de la consideración de "bestia negra" que pintaban sus encarnizados enemigos. Incluso se llegó a transigir con la figura del general, teniendo en cuenta que muchos falangistas tenían por él un aprecio de tipo irracional, sentimental. La crítica a que se le sometia se justificaba en que, triunfador de una guerra y con inmensas posibilidades de actuación, no había realizado la revolución necesaria. La figura del Generalísimo producía chispas entre los distintos sectores azules, porque los francofalangistas, agazapados a la sombra de una figura histórica, justificaban en la obra de creación del Régimen su pasado politico.

El continuismo monárquico era ferozmente atacado desde el FES, pero no quedaba en ello tal actitud. Cuando se inició el proceso de transformación a monarquía constitucional siguió la crítica. El FES había iniciado una campaña sin final contra la monarquía partiendo del peculiar republicanismo histórico de la Falange, en la faceta de continuismo regiminista que representaba y en la falta de igualdad de oportunidades que entrañaba esa forma del gobierno. En su época de repliegue el FES esbozaba confusos planteamientos que optaban por un Consejo de Estado en donde estuvieran representadas las ramas más importantes de la nación. Lejos quedaban ya los conceptos de República de trabajadores a donde parecía conducir la insistente propaganda de la «República Sindical» realizada años atrás.

La desaparición del Movimiento Nacional arrastró también la casi extinción de los grupos falangistas. Esta fue una más de las contradicciones que fueron apareciendo con el transcurrir del tiempo. La negativa al 
jefe carismático y la aparición siempre de Hillers como el "todopoderoso" en los distintos núcleos o el escaso eco tenido entre la juventud, a pesar del grado de idealismo que suponian en ella, fueron otras de las muchas contradicciones que generaron. Su fracaso político resultó evidente, mas para una organización que se definía sobre todo por el compromiso militante y que entendía antes que el triunfo político la asimilación de una ética muy precisa aquella etapa de juventud pudo haber merecido la pena. 